\title{
BMJ Open Multistakeholder perspectives on the strengthening and embedding of mandatory continuing medical education in Georgia: a qualitative study
}

\author{
Ekaterine Ruadze, ${ }^{1}$ Ekaterine Cherkezishvili, ${ }^{2}$ Elisa Roma, ${ }^{3}$ Kieran Walsh (D) , ${ }^{4}$ \\ Tamar Gabunia, ${ }^{5}$ Amiran Gamkrelidze ${ }^{6}$
}

To cite: Ruadze E, Cherkezishvili E, Roma E, et al. Multistakeholder perspectives on the strengthening and embedding of mandatory continuing medical education in Georgia: a qualitative study. BMJ Open 2021;11:e052686. doi:10.1136/ bmjopen-2021-052686

- Prepublication history for this paper is available online. To view these files, please visit the journal online (http://dx.doi. org/10.1136/bmjopen-2021052686).

Received 25 April 2021 Accepted 24 November 2021

Check for updates

(C) Author(s) (or their employer(s)) 2021. Re-use permitted under CC BY-NC. No commercial re-use. See rights and permissions. Published by BMJ.

For numbered affiliations see end of article.

Correspondence to

Dr Kieran Walsh;

kmwalsh@bmj.com

\section{ABSTRACT}

Objective Continuing medical education (CME) is a vital component of health systems. Setting up a CME system is a complex task, requiring involvement of stakeholders including educators, learners, institutions and policy makers. The aim of the study was to conduct qualitative research involving multiple stakeholders to explore the perceived effectiveness and shortcomings of the CME system in Georgia, its place in the health system and potential means of improving it.

Design This is a qualitative study. All data were collected using semistructured individual interviews. The questions were derived from the relevant literature. Data analysis was conducted using comparative strategy.

Participants We interviewed individuals from CME providers, medical establishments, the professional development board (PDB), and the Regulatory Agency for Medical and Pharmaceutical Activities. We thus interviewed 23 people (11 people from CME providers, 8 people from medical establishments, 3 PDB members and 1 person from Legal Entity under Public Law Regulatory Agency for Medical and Pharmaceutical Activities). Results Georgia has had experience of mandatory CME in the past, which had been criticised for its poor quality and bureaucratic processes. CME is viewed as an essential developmental process for medical professionals, the outcome of which is to deliver high-quality medical care. Our interviewees identified a clear need for high-quality CME courses. However, significant challenges that need to be overcome include financial barriers, doctors' attitudes to $\mathrm{CME}$, a lack of CME courses in all medical specialties and relatively weak professional associations.

Conclusion CME is widely recognised as an essential pillar in providing quality medical care. Establishing high-quality CME requires a strategic and holistic approach. In order to ensure the sustainable and effective implementation of the CME process, we need to take into account stakeholders' interests and expectations, the socioeconomic status and development of the country, and past experiences of all relevant individuals and organisations.

\section{INTRODUCTION}

Health systems strengthening is defined as 'any array of initiatives and strategies that
Strengths and limitations of this study

- The methodology chosen for this study meant that the research was carried out on stakeholders from a diverse range of backgrounds.

- Semistructured individual interviews provided time and scope for participants to give detailed information about their opinions regarding their continuing medical education (CME) experience, barriers to mandatory CME and future visions.

- Although the study provides the views of many different stakeholders on CME, we did not seek the views of patients and the wider public.

- This was a study that was carried out in Georgia; there may be limited generalisability to other countries.

improves one or more of the functions of the health system and that leads to better health through improvements in access, coverage, quality or efficiency'. ${ }^{1}$ It has been increasingly recognised that health system strengthening is only possible if there are adequate human resources for health who are competent to deliver care that patients and populations need. $^{2}$

However, countries will not have highquality human resources for health without a robust system of continuing medical education (CME) or continuous professional development (CPD).

CME may be defined as 'any activity that is intended to maintain, develop or increase the knowledge, skills, and professional performance and relationships that a physician uses to provide services for patients, the public, or the profession'. ${ }^{3}$ CME is a vital component of health systems. A CME system is a system whereby CME is regulated and made available to healthcare professionals. Setting up a CME system is a complex task. It involves balancing the needs of multiple stakeholders 
including educators, learners, institutions and policy makers. The first step in setting a system of CME is legislative change so that $\mathrm{CME}$ is recognised and providers are accredited. The next phase involves the implementation and roll-out of the newly established system. During this phase, all those involved in CME will need a lot more detail on how CME will work in practice. As Filipe et al have written, 'of all medical education stages, CME is the least formally structured and can be the most complex to create and assess given the diversity of curricula, educators, regional healthcare needs, professional aspirations, complexity of working environment and multiple stakeholders'. ${ }^{4}$ This highlights the importance of multistakeholder involvement when setting up CME programmes. This is vital to ensure that CME is more than just a 'topdown' directive and that it is transformed into an active programme that will make a real difference to healthcare professionals' practice. There is increasing evidence of the effectiveness of CME. ${ }^{5}$ Also, the attempts to align CME with quality improvement have been promoted by professional organisations. ${ }^{6}$ This will also ensure that barriers to the implementation of CME are overcome. ${ }^{7}$ These barriers might include doctors' resistance to change, the culture of learning, uniprofessional learning, lack of infrastructure for CME, technological barriers (in the case of e-learning), time and financial incentivesat individual and institutional levels. The perspectives of multiple stakeholders are also necessary to ensure that accredited CME is valued and that mandatory CME is actually implemented.

CME systems in high-income countries have been extensively studied, ${ }^{8}$ but there is much less information on the same issue in low-income and middle-income countries.

These perspectives are not always sought out, and this qualitative study was developed to help address this gap by carrying out in-depth interviews with representatives of these groups within Georgia. However, before explaining what and how we did this, we give a brief outline below of the background to CME in Georgia.

\section{BACKGROUND TO CME IN GEORGIA}

The Georgian health system has undergone major changes in the past three decades-one of these included the privatisation of $90 \%$ of health facilities. ${ }^{9}$ The CME system in Georgia has experienced similar changes. The CME system of the independent state of Georgia started in 2001. ${ }^{10}$ From 2001 until 2006, the state entity Georgia State Medical Academy (which later merged with the Tbilisi State Medical University) was responsible for doctors' residency programmes and CME courses. ${ }^{9} 11$ From 2001 to 2007, CME was compulsory, and the country's CME system based on recertification and accumulation of CME points was developed. However, in a 2008 reform, the recertification mechanism for doctors was cancelled; doctors were awarded lifetime certificates; and CME was no longer mandatory. ${ }^{12}$
Nowadays, physicians in Georgia obtain their certificate of independent medical activity for their lifetime and participate in CME activities only on a voluntary basis. The only exception relates to perinatal service providers. A ministerial order amendment issued on 2 September 2020 on 'The Levels of Regionalization of Perinatal Services and Patient Referral Criteria' stipulates that obstetriciangynaecologists, neonatologists, radiologists, anaesthesiologists and specialists in resuscitation working for antenatal and perinatal service providers should participate in CME activities. ${ }^{13}$ According to a ministerial decree issued on 15 August 2018, a 'professional development board' (PDB) was established at the Ministry of Internally Displaced Persons from the Occupied Territories, Labour, Health and Social Affairs (hereafter the 'Ministry') . ${ }^{14}$ Secretarial and technical support to the PDB is provided by the Legal Entity under Public Law (LEPL): Regulatory Agency for Medical and Pharmaceutical Activities. Among many other functions related to medical education, the board (1) develops criteria and rules for accreditation of postdiploma CME programmes and submits them to the Minister for approval; (2) provides accreditation for higher medical establishments, and (3) monitors accredited organisations and, based on the results of monitoring, continues or cancels their accreditation. ${ }^{14}$

To qualify as CME providers, organisations need to submit an application with at least two recommendations from field experts to the PDB. Face-to-face CME course providers must (1) inform the PDB about the date and place of planned courses during the last week of each month; (2) inform the board about the number of participants, their names and specialties, as well as the names of the trainers and the number of hours they spent preparing the training-all no later than 3 days before the start of the course; (3) keep a registry of the course and participants; (4) implement the course internal quality assessment procedures; and (5) assess participants in a final exam. Assessment methods during the final exam can be in different formats. If the assessment method is a multiple-choice test, more than $75.5 \%$ of questions must be answered correctly. ${ }^{1516}$

\section{Aim of the study}

The study aimed to explore multiple stakeholder perspectives of the perceived effectiveness and shortcomings of CME in Georgia as well as attitudes to future developments.

The following research questions were investigated:

1. What are the shortcomings of the existing practice of CME in Georgia from different stakeholders' perspectives?

2. How do different stakeholders perceive voluntary CME and mandatory CME?

3. How do different stakeholders see the future of CME and what barriers to CME should be addressed?

\section{METHODOLOGY}

Our research is within the constructionist research paradigm. In this paradigm, knowledge is constructed and 
reconstructed and resides in the interactions of social, cultural and interpersonal factors. ${ }^{17-19}$ Accordingly, multiple realities exist, and these are dependent on mutual interactions between researchers, respondents and the context of the research. In our research on CME in Georgia, the researchers' assumptions and experience, as well as what influence they have on data collection and analysis, are important and so are shared further to facilitate interpretation of the research findings. ${ }^{20}$

ERu has a background in epidemiology and had experience in conducting qualitative and quantitative studies. She also teaches in the faculty of medicine. EC has a great deal of experience in implementing CME programmes in Georgia. ERo and KW have a great deal of experience in implementing CME programmes internationally. TG and $A G$ have experience in senior leadership positions in healthcare and in implementing policy in medical education and public health.

\section{Setting, participants and procedures}

We adopted a non-probability purposive sampling to select study participants.

As a first step, we identified CME stakeholders: the PDB at the Ministry, LEPL Regulatory Agency for Medical and Pharmaceutical Activities, CME providers and medical universities/faculties of medicine, primary healthcare providers, hospitals and medical doctors.

In the next step, we selected participants from each stakeholder group. Sample size was mainly determined by the study aim-that is, we wanted to give multiple stakeholder perspectives, which by themselves were highly specific. For example, we aimed to explore the study questions with CME providers of varying sizes as we judged that their experience and vision of CME might be different and so might bring additional information. We also planned to employ good interview time management, allowing enough time and space for respondents, by choosing the preferred date and period of day for the respondents. ${ }^{21}$

\section{Selection of CME providers}

At present, in Georgia, there are about 60 CME providers, offering more than 200 courses in different specialties. The number of courses offered per provider ranges from 1 to 52. As we wanted to hear from the CME providers that run 52 courses as well as CME providers that run only a few courses, we developed the following approach: (1) for CME providers with more than eight CME courses per year, one interview per provider was held; we had four such providers, and therefore, four interviews in total were collected; (2) out of four CME providers with five to seven CME courses per year, we interviewed two; (3) from $52 \mathrm{CME}$ providers with four or fewer courses, we sampled four CME providers with simple random sampling; (4) there are only two providers mainly conducting CME courses for family medicine doctors. As we wanted to obtain their point of view as well, we selected both of them. So, in total, we selected $12 \mathrm{CME}$ providers.

\section{Selection of primary healthcare and hospital providers}

The starting selection point of medical establishments (hospitals and primary healthcare providers) is the specialties mostly covered by the CME courses. We identified the following specialties: obstetricians and gynaecologists, family medicine doctors, paediatricians and neonatologists, emergency physicians and dentists. Based on this finding, we decided to approach the medical directors of the following establishments: (1) maternity homes, (2) polyclinics/ambulatories, (3) children's hospitals and (4) ambulance services. With convenience sampling, we selected two medical establishments from each domain. In total, there were eight interviews.

\section{Professional development board}

From the PDB at the Ministry, with convenience sampling, we selected three members.

\section{LEPL regulatory agency}

From the LEPL Regulatory Agency for Medical and Pharmaceutical Activities, we interviewed one person.

\section{Ethics}

ERu contacted all prospective participants through telephoning or emailing them. During the initial contact, the purpose of the study was explained, and participants were informed that the interview will be audio-recorded. Participants were assured of the confidentiality of the recordings and ERu explained that their participation was voluntary and that they could stop the interview at any time.

If they agreed to participate (after verbal consent) in the study, we emailed them a consent form and agreed on the date of an interview. The interview took place only after we received the signed form.

Based on the respondents' preference (taking into account the COVID-19 pandemic), we had either face-toface, video conference or telephone interviews.

\section{Interviews}

All data were collected using semistructured individual interviews. Semistructured interviews are frequently used in qualitative research. Semistructured interviews provide researchers the flexibility to diverge in order to pursue an idea or response in more detail. ${ }^{22} 23$

All interviews were conducted by ER to ensure uniformity. Interviews were held through Zoom, Viber, telephone and face-to-face. During the interview, nobody else presented besides the respondent and the researcher. Interviews lasted from 30 to $40 \mathrm{~min}$. Interviews provided time and scope for participants to give detailed information about their opinions regarding their CME experience, barriers to mandatory $\mathrm{CME}$ and future visions. The questions were derived from the literature. ${ }^{24}{ }^{25}$ During the interviews, ER probed and sought clarification or elaboration of participants' responses as needed. The questions were evaluated by all members of the team who have different levels of experience in qualitative research 
and medical education (including CME). No repeated interviews were conducted.

\section{Data analysis methods}

After each interview, notes were made and transcripts were prepared from all recorded interviews. Data analysis was conducted using comparative strategy. By highlighting similarities and differences, we formed concepts as the basic units of analysis. What we did was look at similarities, differences, patterns and regularities between categories. This involved regrouping initial categories and defining new ones (as needed). Initially, by highlighting similarities and differences, we formed concepts as the basic units of analysis. Open coding was performed by $\mathrm{ERu}$, who initially applied as many codes as needed (eight codes initially) and gave conceptual labels. Conceptually, similar experiences were grouped together to form categories. $^{26}$

Such an approach was used within stakeholder analysis. To move from categories to concepts, axial coding, consisting of intense analysis done around one category at time, was performed. ${ }^{27} 28$ This was how we identified dominating themes. All members of the research team discussed and agreed on the results. Data collection and analysis were conducted simultaneously.

In the beginning of the research, the stakeholder analysis was done. As we aimed to explore the perceived effectiveness and shortcomings of the CME system from different perspectives, we interviewed the following stakeholders: Regulatory Agency for Medical and Pharmaceutical Activities, PDB, CME providers, and primary healthcare and hospital care providers. As they all play their own specific role in CME, we decided to analyse them separately. We merged the themes at the final stage when we already had themes identified per stakeholder.

\section{RESULTS}

Twenty-three respondents from five stakeholder institutions participated in semistructured interviews lasting 30-40 min each during the study period, OctoberDecember 2020. As we wanted to obtain multiple stakeholder perspectives, 24 was the initial planned number of respondents. We did not manage to interview one CME provider. Due to the COVID-19 pandemic, we did not manage to agree on a time, even after four follow-up calls. Table 1 presents the demographic characteristics of study participants.

Following data collection and analysis as previously described, we generated three themes, which are described as follows.

\section{Theme 1: the existing practice of CME and its challenges}

At present, CME is not mandatory for all specialties. However, the fact that the country has managed to keep the CME accreditation process up and running was viewed positively by all respondents. The CME course accreditation process is considered to be appropriately designed

\begin{tabular}{lcc}
$\begin{array}{l}\text { Table 1 } \\
(\mathrm{n}=23)\end{array}$ & Demographic characteristics of study participants \\
\hline Variable & Frequency & $\%$ \\
\hline Age category (years) & & \\
\hline $30-40$ & 8 & 35 \\
\hline $41-50$ & 2 & 8 \\
\hline Above 50 & 13 & 57 \\
$\begin{array}{l}\text { Gender } \\
\text { Female }\end{array}$ & 11 & 47 \\
\hline Male & 12 & 53 \\
\hline Stakeholder category & & \\
$\quad$ Professional development board & 3 & 13 \\
\hline $\begin{array}{l}\text { Regulatory agency for medical and } \\
\text { pharmaceutical activities }\end{array}$ & 1 & 4 \\
\hline CME provider (different specialties) & 11 & 47.6 \\
\hline Head of the maternity home & 2 & 8.6 \\
\hline Head of the emergency services & 2 & 8.6 \\
\hline Children's hospitals & 2 & 8.6 \\
\hline Head of ambulatory service & 2 & 8.6 \\
\hline
\end{tabular}

$\mathrm{CME}$, continuing medical education.

and well managed. There is an exact list of documents that need to be submitted; deadlines are clear; and the whole process is straightforward.

Some respondents talked about problems obtaining updated information about CME courses.

It is not easy to find the CME course you need. The website is not user-friendly, and information about forthcoming CME courses not well described, that is, lecturers, dates of the course, fees, Professional Development Unit (PDU) scores, etc. There are no support services at all. (CME provider)

The provider is currently mandated to submit the list of attendees 3 days in advance of the accredited CME course. This poses a number of challenges as doctors are often not able to accurately predict their availability. Thus, this requirement poses challenges both for the providers and potential learners.

I have to submit the list of participants in advance, during the CME application submission process. You have to apply at least ten days before the course. Doctors are very busy, and if some doctors cannot attend, and some places became vacant, I cannot offer this place to another doctor...Well, they can attend, but they cannot earn scores. (CME provider)

Obtaining references from professional associations might be challenging for some CME providers, especially if the association provides a rival course.

One of the documents to be submitted to the accreditation board is the letter of recommendation (two letters of recommendation). One letter should be 
from a professional association, which might be problematic if this professional association considers you a rival. (CME provider)

One provider mentioned that the accreditation board refused accreditation of their course, as they could not see the course's necessity, and she thinks that the board should be able to think 'out of the box' or that they could seek expert opinion on this subject.

Accreditation committee members should represent more fields of medicine as they are right now. If they see the submitted course is not within their competency, they should invite experts in the field to evaluate the course's necessity. There should be small committees based on the course that needs to be accredited. The committee should be multi-discipline and be able to evaluate specific courses. (CME provider)

One major challenge that was mentioned by almost all respondents was lack of quality monitoring of existing CME courses.

There are two aspects of CME courses: technical and contextual. The LEPL Regulatory Agency for Medical and Pharmaceutical Activities monitors the course's technical aspects (eg, the format of the course, who is the lecturer, number of course attendees, do they have a questionnaire or not, and venue of the course) and the assessment of course content rests with professional associations.

Technical aspects have improved over the years and now are better managed than the quality monitoring of the CME courses.

...Technical aspects are important to be checked. When we first started the CME many years ago, providers did not know how to write; they had no idea that it needed aims and objectives, methods, Etc. These are skills which we learned, and this is important. (Professional development board)

The majority of respondents felt that the monitoring of the actual implementation of CME courses needs to be improved. This would become more challenging if CMEs were to be mandatory for every specialty. The increased number of courses will increase the demand for quality monitoring.

...We do not have quality monitoring of the CME courses. To do quality monitoring of face-to-face courses requires many resources. (Professional development board)

All respondents felt that the course quality monitoring process could be further improved by involving more professional associations during the course assessment process at the stage of accreditation.

\section{Theme 2: attitude to CME}

Attitudes to CME are not homogeneous. While all respondents recognise the importance of $\mathrm{CME}$, they also mentioned that not all doctors see CME as a crucial activity for their professional growth. According to some respondents, such views are age dependent.

I know doctors who did not attend any educational course in the last 10-15 years of their professional life. They say that they know enough and have enough experience and knowledge, and say that they do not expect to learn anything new from courses. (Head of hospital)

Younger doctors are much eager to attend CME courses and to learn more than middle-aged or oldaged doctors. They say: “... I know everything, it is elementary, I do not need to learn more". (Head of ambulatory services)

... They always try to postpone the participation in training/CME course, they always have an excuse. They say: "...I'll do after the annual leave". (Head of ambulatory services)

According to our respondents, financial barriers are yet another problem especially for doctors living outside of the capital-online CME courses as well as in-house CME courses are viewed as a good solution to the problem.

Medical doctors working and living in the regions find it financially challenging to attend face-to-face courses in the capital, as they have additional costs for accommodation. In such cases online courses are particularly important as they save both time and money. Alternatively, more CME courses could be offered at doctors' workplaces. In-country CME events as well as international conferences are more affordable and accessible for doctors living in the capital than those in the regions. (CME provider)

Online education is the future of education. However, online cannot replace colleagues' face-to-face meetings and discussions. (Professional development board member)

\section{Attitudes to mandatory CME}

According to the majority of our respondents, there is a clear need for mandatory high-quality CME courses to be made available in the country. Most respondents felt that mandatory CME would ensure that all doctors were continually learning and thus improving their standards.

...A doctor can practice many years without getting new information, without participating in CME courses. (Head of children's hospital)

CME should be mandatory, as there is a severe lack of willingness of self-education. (Head of children's hospital)

Some of our respondents mentioned that, in past years when CME was mandatory, some doctors did not even attend the courses but paid money to get certificates of attendance. Their motivation was just to get 
certificates and credits and not to achieve real professional development.

...The old system of mandatory CME was good for such inert doctors. It is clear that if you are not interested in the course, you will not get much. However, you will get something. Motivation is important. The motivation for them to participate in CME courses was to earn PDUs and renew the certificate. (Head of children's hospital)

Some respondents fear that if CME becomes mandatory again, it could just be a formality and low quality. Instead, it should be a means whereby doctors can truly develop and grow.

Some respondents argued that voluntary CME courses based on competition between providers are of higher quality than mandatory courses.

If a doctor participates in CME because they are motivated of their own free will to develop further and get updated knowledge, then they will only go to high-quality courses. As a result, the demand for high-quality courses increases. If the doctor is not motivated and cannot see their professional growth with career progress, they do not seek high-quality courses, and the demand for high-quality courses decreases. (CME provider)

\section{Theme 3: future of CME}

For the majority of respondents, mandatory CME is an absolute must, which requires a step-by-step approach.

We cannot make mandatory CME for all specialties at once, as we do not have enough accredited CME programs in many fields of medicine. Not only new programs should be created but also the existing programs should be renewed. (Regulatory Agency for Medical and Pharmaceutical Activities)

All respondents think that any mandatory CME implementation process should be transparent for doctors, and therefore, constant and consistent communication with medical professionals is essential.

Doctors should know what to expect and in what time frame. Enough time should be given to doctors to prepare. They should be informed at least a year ahead about the beginning of the process. (Professional development board member)

The preparatory process for reintroducing mandatory CME should be thorough and should take into consideration the many challenging aspects of CME. According to our respondents, the main problem is mindset and mentality, that is, doctors' vision of their professional development.

We have lost the middle generation of doctors. Young and senior professionals are very active but not middle-aged professionals. We need better communication with doctors. (Professional development board member)

Some respondents mentioned that academic staff should not be able to opt out of the CME process: if they work as doctors, they should earn CME credits and be involved in the recertification process. Each doctor involved in the CME process should have their own online portfolio to plan and monitor their participation in CME.

The major protests against the mandatory CME in 2001 came from the academic staff because the PDU accumulation process was not well explained for them. They did not realize that the fact that they supervise the Ph.D. candidate, or when they teach or prepare presentations can earn PDUs. (Professional development board member)

If $\mathrm{CME}$ becomes mandatory, the recertification process should be reintroduced.

...I reckon that the recertification process should become part of the culture. The recertification process should be smooth and flexible. Recertification should be automatic based on the accumulated PDUs. (Professional development board member)

The language barrier for some ethnic groups living in Georgia is yet another problem that should be solved. There are areas populated mainly by ethnic Azeris and Armenians who do not speak any Georgian.

The re-introduction of mandatory CME and recertification should consider Azeri and Armenian doctors' requirements - some may not be familiar with the Georgian language. (Professional development board member)

One major challenge to the future development of CME is the financial barrier. From the data, we could not generate a uniform approach as to how this should be solved. However, respondents feel that CME course fees should be regulated. CME course providers should not be motivated by the number of course attendees and the doctors' participation in CME courses should be financially supported not for all but at least for some doctors.

Clinics at least periodically should financially support doctors' participation in CME courses. (Regulatory Agency for Medical and Pharmaceutical Activities)

Financial support should be given to doctors in lowincome specialties, doctors from rural mountainous regions, primary healthcare or public health professionals. (CME provider)

The financial scheme of CME should be mixed. Course fees should be affordable for doctors. Exceptional financial support may be needed for medical personnel from low-income and mountainous region. (Professional development board member) 
Strong professional associations are viewed as a crucial point for providing high-quality CME courses.

On the one hand, professional associations should play a key role in developing CME in Georgia. They should create accredited programs and be involved and lead the CME process, much more actively than they currently are. (Regulatory Agency for Medical and Pharmaceutical Activities)

According to many respondents, CME should focus on strengthening primary healthcare services. Some respondents argued that primary healthcare doctors lack updated knowledge and skills, especially primary healthcare doctors working in the regions.

Primary healthcare is relatively weak. If primary healthcare were more robust than it is now, patients do not accumulate in the capital. The burden of care will be shared. Fortunately, we have a well-developed medical infrastructure in regions, and if doctors are well trained, the quality of care can be high in regions as well. The quality of healthcare will be improved, and step by step, we will move towards decentralisation. (CME provider)

... Primary healthcare doctors should know how to monitor their patients as $3 / 4$ th of the job should be done by the patient. For example, in diabetes, the patient should take good care at home to not develop blood vessels, kidney, and heart problems. Primary healthcare doctors cannot monitor patients' behaviour at home. Doctors should know their competency limits in patients' management and up to what extent they can intervene, and who and what can help. They need training. (Head of maternity home)

\section{DISCUSSION}

\section{Principal findings}

Georgia has had experience of mandatory CME in the past, which had been criticised for its poor quality and bureaucratic processes. CME is viewed as an essential developmental process for medical professionals, the outcome of which is to deliver high-quality medical care. Our interviewees identified a clear need for highquality CME courses. However, significant challenges that need to be overcome include financial barriers, doctors' attitudes to CME, a lack of CME courses in all medical specialties, relatively weak professional associations and language barriers for some ethnic groups. Furthermore, on a broader political level, Georgia is looking to align the quality and breadth of its medical practice and continuing professional development to European standards. According to the European Commission Report, accreditation of programmes in Europe is more common than accreditation of providers $(48 \%$ vs $30 \%){ }^{5}$ It may be that Georgia should consider reforming its systems so that it accredits providers. With the challenges of the accreditation process mentioned previously, this also might be the direction that needs to be exploredcoming with the obvious advantages such as decreasing the administration expenses and making the process much more efficient. The European Union of Medical Specialties (UEMS) is a representative organisation for specialist doctors from the national associations of all European Union/European Economic Area (EU/EEA) states and a number of non-EU/EEA countries. Georgia and its neighbouring countries, Armenia, Azerbaijan and Turkey, are members of UEMS. The policy of the UEMS on CPD relies on the Basel Declaration, issued on 20 October 2001. ${ }^{29}$ The Basel declaration is in line with the challenges and needs identified in the Georgian context. According to the Basel Declaration, the goal of CME is to improve all aspects of the medical practitioner's performance, incorporating the principles of adult learning. It is expected that the doctor should assess their educational needs and identify the means of addressing these needs. CME is described as a part of quality improvement 'that ensures that good doctors remain good and get better'. ${ }^{29}$ Funding, time and continuous peer support are identified as resources required for $\mathrm{CME}$ and viewed as pillars without which the implementation process of CME will fail. A range of educational activities must be made available to doctors. The learning culture in medicine must be developed further, and doctors' educational activities must be valued and supported.

There are many theories of how adults learn, how they participate in CME programmes and how they develop attitudes to these programmes. One unifying theory that may explain some of these attitudes to CME is selfregulated learning theory. Self-regulated learning refers to the "modulation of affective, cognitive and behavioural processes throughout a learning experience in order to reach a desired level of achievement'. ${ }^{30}$ In effect, this means that learners 'go through a cyclic process of setting learning goals, choosing learning strategies and assessing progress towards goals'. ${ }^{30}$ This may be a good fit with the attitudes of the doctors towards CME. They would like to do CME that is based on their own needs; they would like to choose learning strategies that are high quality, accessible, low cost and comprehensive, and they would like to ensure that their CME helps them to progress towards their goal of quality improvement.

\section{Strengths and weaknesses}

The themes that emerged from the interviews with stakeholders were consistent. Although the study provides the views of many different stakeholders on CME, we still lack the views of patients and the wider public. We hope to look at this in research to be undertaken in the future. All respondents are medical doctors. In our study, we did not interview them because they are practitioners, but rather because they also are working as head of the department, head of the hospital or head of the association, or are members of the board. In that regard, the study findings represent the view of various stakeholders involved in the 
decision-making process about CME. This was a study that was carried out in Georgia-there may be limited generalisability to other countries. CME is also an issue that is important to generalists. CME regulations usually apply to all doctors, and so generalists should find the outcomes of this study of interest. Lastly, this is a topical subject. The COVID-19 pandemic has made accessing CME courses an even greater challenge for many doctors, and so seeking the views of different stakeholders on CME is likely to be relevant and timely.

\section{CONCLUSION}

CME is widely recognised as an essential pillar in providing quality medical care. High-quality CME is a challenging process and requires a strategic and holistic approach. In order to ensure the sustainable and effective implementation of the CME process, stakeholders' interests and expectations, the socioeconomic status and development of the country, and past experience of all stakeholders should be taken into consideration. This study and the broader literature suggest that Georgia should reform its system of CME so that it is high quality, accessible, low cost, comprehensive, based on learner needs and part of wider initiatives that will drive quality improvement. Practical reforms that enable this to happen will likely also address doctors' attitudes to CME and make them more willing to take up the CME opportunities that are available.

\section{Author affiliations}

${ }^{1}$ Global Fund Projects' Implementation Unit, National Center for Disease Control and Public Health, Tbilisi, Georgia

${ }^{2}$ BMJ Partnership Team, BMJ, Tbilisi, Georgia

${ }^{3}$ Global Health Team, BMJ, London, UK

${ }^{4}$ BMJ Partnership Team, BMJ, London, UK

${ }^{5}$ First Deputy Minister of Internally Displaced Persons from the Occupied Territories, Labour, Health and Social Affairs, Ministry of Internally Displaced Persons from the Occupied Territories, Labour, Health and Social Affairs, Tbilisi, Georgia ${ }^{6}$ Director General's Office, National Center for Disease Control and Public Health, Tbilisi, Georgia

Acknowledgements We are grateful for Georgian CME providers, medical establishments (hospitals and ambulatory clinics), the professional development board and the LEPL Regulatory Agency for Medical and Pharmaceutical Activities.

Contributors ERu conducted the interviews, analysed the data, wrote the first draft and approved the final version. KW, ERo and EC contributed to the design of the work, critically revised the drafts and approved the final version. AG and TG contributed to the conception of the work, revised the drafts and approved the final version. ERu acts as the guarantor.

Funding The authors have not declared a specific grant for this research from any funding agency in the public, commercial or not-for-profit sectors.

Competing interests $\mathrm{KW}$ and $\mathrm{ER}$ are employees of $\mathrm{BMJ}$, which produces resources that are used for CME. EC leads the country implementation efforts of BMJ in Georgia. ER was contracted as consultant for the duration of the study.

Patient and public involvement Patients and/or the public were not involved in the design, conduct, reporting or dissemination plans of this research.

Patient consent for publication Not applicable.

Ethics approval This study involves human participants and was approved by the institutional review board (IRB) (IRB00002150) at the National Center for Disease Control and Public Health on 23 September 2020 (letter \# 2020-057). Participants gave informed consent to participate in the study before taking part.
Provenance and peer review Not commissioned; externally peer reviewed.

Data availability statement Data are available on reasonable request. There are no quantitative data associated with this study.

Open access This is an open access article distributed in accordance with the Creative Commons Attribution Non Commercial (CC BY-NC 4.0) license, which permits others to distribute, remix, adapt, build upon this work non-commercially, and license their derivative works on different terms, provided the original work is properly cited, appropriate credit is given, any changes made indicated, and the use is non-commercial. See: http://creativecommons.org/licenses/by-nc/4.0/.

\section{ORCID iD}

Kieran Walsh http://orcid.org/0000-0003-1268-4676

\section{REFERENCES}

1 Islam M, ed. Health Systems Assessment Approach: A How-To Manual. Submitted to the U.S. Agency for International Development in collaboration with Health Systems 20/20, Partners for Health Reformplus, Quality Assurance Project, and Rational Pharmaceutical Management Plus. Arlington, VA: Management Sciences for Health, 2007.

2 De Savigny D, Adam T, De Savigny D, et al. Systems thinking for health systems strengthening. alliance for health policy and systems research, who, 2009. https://www.who.int/alliance-hpsr/resources/ 9789241563895/en/

3 Shumway JM, Harden RM, No AG, Association for Medical Education in Europe. AMEE guide No. 25: the assessment of learning outcomes for the competent and reflective physician. Med Teach 2003;25:569-84.

4 Filipe HP, Golnik K, Patel D. What do you need to know to set up CPD as a professional body? Community Eye Health 2017;30:11-13.

5 Reeves S, Pelone F, Harrison R, et al. Interprofessional collaboration to improve professional practice and healthcare outcomes. Cochrane Database Syst Rev 2017;6:CD000072.

6 Davis NL, Davis DA, Johnson NM, et al. Aligning academic continuing medical education with quality improvement: a model for the 21st century. Acad Med 2013;88:1437-41.

7 O'Brien Pott M, Blanshan AS, Huneke KM, et al. Barriers to identifying and obtaining CME: a national survey of physicians, nurse practitioners and physician assistants. BMC Med Educ 2021;21:168.

8 European Commission. Study concerning the review and mapping of continuous professional development and lifelong learning for health professionals in the EU | public health. Available: https://ec.europa. eu/health/workforce/key_documents/continuous_professional_ development en

9 Richardson E, Berdzuli N. Georgia: health system review. Health Syst Transit 2017;19:1-90.

10 Edict of the President of Georgia on "Postgraduate medical education system and health care human resource management development" \#478 issued on 24/11/2001. Available: https://www. matsne.gov.ge/ka/document/view/115330?publication=0

11 Edict of the President of Georgia on "Reorganization of the State Medical Academy" \#226 issued on 24/03/2006. Available: https:// matsne.gov.ge/ka/document/view/97684?publication=0

12 Amendment issued on 21/03/2008 to the law of Georgia on medical practice. Available: https://matsne.gov.ge/en/document/view/15334? publication $=17$

13 Ministerial order \#01-99/5, 2nd of September 2020, amendment of the ministerial decree \#01-2/6, 15th of January 2015 on "The Levels of Regionalization of Perinatal Services and Patient Referral Criteria". Available: https://matsne.gov.ge/ka/document/view/4941327? publication $=0$

14 Ministerial order 01-9/6, 15th of August 2018, on "Establishment of Professional Development Board and its general provisions". Available: https://www.matsne.gov.ge/ka/document/view/4296069? publication $=0$

15 Ministerial order \#01-3/6, 19th of July 2018, on "Forms of continuous medical education and rules and criteria for accreditation, as well as rules of professional rehabilitation and adequate programs accreditation criteria". Available: https://matsne.gov.ge/ka/ document/view/4265442?publication=0

16 Ministerial order \# 01-38/6 2nd of May 2019 amending several provisions from Ministerial decree \#01-3/6, 19th of July 2018. Available: https://matsne.gov.ge/ka/document/view/4536679? publication $=0$

17 Talja S, Tuominen K, Savolainen R. "Isms" in information science: constructivism, collectivism and constructionism. J Doc 2005;61:79-101. 
18 Harre R. Public sources of the personal mind: social constructionism in context. Theory Psychol 2002;12:611-23.

19 Varpio L, Ajjawi R, Monrouxe LV, et al. Shedding the cobra effect: problematising thematic emergence, triangulation, saturation and member checking. Med Educ 2017;51:40-50.

20 Mills J, Bonner A, Francis K. The development of Constructivist Grounded theory. Int J Qual Methods 2006;5:25-35.

21 Malterud K, Siersma VD, Guassora AD. Sample size in qualitative interview studies: guided by information power. Qual Health Res 2016;26:1753-1760.

22 Gill P, Stewart K, Treasure E, et al. Methods of data collection in qualitative research: interviews and focus groups. $\mathrm{Br}$ Dent $J$ 2008;204:291-5.

23 Britten N. Qualitative research: qualitative interviews in medical research. BMJ 1995;311:251-3.

24 Chakhava G, Kandelaki N. Overview of legal aspects of continuing medical Education/Continuing professional development in Georgia. J Eur CME 2013;2:1923.

25 Beraia G, Surguladze V, Giorgadze T. Problematics and importance of continuous medical education in Georgia. $¥ 65 y 33 \delta$

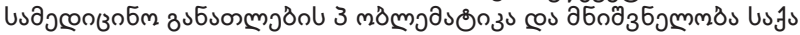

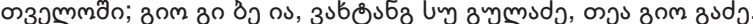

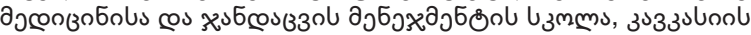

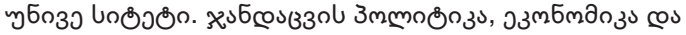

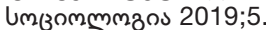

26 Juliet Corbin 1 and Anselm Strauss. Grounded theory research: procedures, Canons, and Evaluative criteria. Qual Sociol 1990;13.

27 Kelle U. "Emergence" vs. "Forcing" of Empirical Data? A Crucial Problem of "Grounded Theory" Reconsidered [52 paragraphs]. Forum Qualitative Sozialforschung / Forum: Qualitative Social Research, 2005. Available: http://nbn-resolving.de/urn:nbn:de:0114fqs 0502275

28 Watling CJ, Lingard L. Grounded theory in medical education research: AMEE guide No. 70. Med Teach 2012;34:850-61.

29 Basel Declaration, UEMS position CPD, D 0120. Available: https:// www.uemssurg.org/ data/assets/pdf file/0005/8438/BASELDeclaration-UEMS-Position-CPD-2001.pdf https://www.uems.eu/_ data/assets/pdf_file/0019/1477/BASEL_DECLARATION.pdf

30 van Houten-Schat MA, Berkhout JJ, van Dijk N, et al. Self-Regulated learning in the clinical context: a systematic review. Med Educ 2018;52:1008-15. 